\title{
ASSESSMENT AND MONITORING OF AGRICULTURAL DROUGHTS IN MAHARASHTRA USING METEOROLOGICAL AND REMOTE SENSING BASED INDICES
}

\author{
Aswathi P. V. ${ }^{1,}{ }^{*}$, Bhaskar R. Nikam ${ }^{1}$, Arpit Chouksey ${ }^{1}$, S. P. Aggarwal ${ }^{1}$ \\ ${ }^{1}$ Water Resources Department, Indian Institute of Remote Sensing, Dehradun, India - aswathipv93@gmail.com
}

Commission V, SS: Disaster Monitoring, Damage Assessment and Risk Reduction

KEYWORD: Standard Precipitation Index (SPI), Effective Drought Index (EDI), Shortwave Angle Slope Index (SASI), Vegetation Condition Index (VCI), Temperature Condition Index (TCI), Vegetation Health Index (VHI)

\begin{abstract}
:
Drought is a recurring climatic event characterized by slow onset, a gradual increase in its intensity, and persistence for a long period depending upon the availability of water. Droughts, broadly classified into meteorological, hydrological and agricultural drought, which are interconnected to each other. India, being an agriculture based economy depends primarily on agriculture production for its economic development and stability. The occurrence of agriculture drought affects the agricultural yield, which affects the regional economy to a larger extent. In present study, agricultural and meteorological drought in Maharashtra state was monitored using traditional as well as remote sensing methods. The meteorological drought assessment and characterization is done using two standard meteorological drought indices viz. standard precipitation index (SPI) and effective drought index (EDI). The severity and persistency of meteorological drought were studied using SPI for the period 1901 to 2015. However, accuracy of SPI in detection of sub-monthly drought is limited. Therefore, sub-monthly drought is effectively monitored using EDI. The monthly and sub-monthly drought mapped using SPI and EDI, respectively were then compared and assessed. It was concluded that EDI serves as a better indicator to monitor sub-monthly droughts. The agricultural drought monitoring was carried out using the remote sensing based indices such as vegetation condition index (VCI), temperature condition index (TCI), vegetation health index (VHI), shortwave angle slope index (SASI) and the index which maps the agricultural drought in a better way was identified. The area under drought as calculated by various agricultural drought indices compared with that of the EDI, it was found that the results of SASI matched with results of EDI. SASI denotes different values for the dry and wet soil and for the healthy and sparse vegetation. SASI monitors the agricultural drought better as compared to other indices used in this study.
\end{abstract}

\section{INTRODUCTION}

Drought is complex natural hazard, which has a slow onset and is defined by the acute water shortage. It is described in many ways depending on its impact and varying characteristics. The prolonged low rainfall marks the onset of meteorological drought, which is followed by hydrological drought as a decrease in the surface water and ground water levels (Hisdal and Tallaksen, 2003), which has a direct effect on the agricultural crops resulting in agricultural drought (Mishra and Singh, 2010). Thus depending on the impact, which drought has on various sectors, it is classified into Meteorological, Hydrological, and Agricultural drought. The effect of drought can be seen worldwide on the livelihood, environment, economy, and overall human well-being.Globally, around 11 million people died due to drought and 2 billion people were adversely affected by drought since 1900 (FAO, 2015). As per the reports from Food Security Information Network, around 108 million people from all around the globe were affected by food insecurity, caused by an El-Nino induced drought (FISN, 2016). India has a long history of drought events, and its impact on the livelihood of people. During

\footnotetext{
${ }^{*}$ Corresponding author
}

the period, 1871 to 2015 , India witnessed around 25 major drought, the one in 1987 was a severe most, a similar drought event repeated in 2002, which affected a population of 285 million people and $59-60 \%$ crop area too. $68 \%$ of the total cropped area in India is drought prone, $33 \%$ of which receives less than $750 \mathrm{~mm}$ of mean annual rainfall (UNICEF, 2015-16). During the years, 2014-15 and 2015-16, major agricultural states were drought affected. The state of Maharashtra, the study area of this work, was severely drought affected in recent years (e.g.1996, 1997, 2001, 2002, 2003, 2004 and 2015). The drought, which occurred in 1996, affected around 266.75 lakh people, settled in 7 districts. Similarly, 17 districts were drought affected during year 1997. Around $50 \%$ of the drought prone area of the state is constituted by the Deccan Plateau, which receives an average annual rainfall of 600 to $750 \mathrm{~mm}$ (NIDM, 2016). Approximately 4.5 million hectares of crop was affected in the 2001 drought.

The agriculture sector gets severely affected by these droughts impacting the livelihood of people depending on it. Taking into consideration, the changing climatic patterns and the irregular rainfalls, the risk of drought occurrence increases (Zhang et al., 2017). Studying the meteorological and agricultural droughts and how it affects the Maharashtra state helps in reduction of the impact of future droughts. Analysis and prediction of droughts is the 
necessity of the hour in the Maharashtra state. Thus, drought monitoring is of immense importance, which may be accomplished by using different remote sensing based and traditional indices. The monitoring of meteorological and agricultural drought can be done using meteorological and remote sensing based indices, respectively.

\subsection{Drought Monitoring Traditional Indices}

The impact of drought is severe as compared to other natural calamities. Drought can be characterized in terms of its severity, spatial extend and persistence. The severity of drought represents how intensely the drought has hit the area, the persistence defines how long the drought remained in the area (WMO, 2016 and GWP, 2016). The meteorological drought, which is marked by a substantial decrease in rainfall, is well monitored using many indices like Rainfall Anomaly Index (RAI), Standard Precipitation Index (SPI), Effective Drought Index (EDI), etc. These meteorological indices are calculated based on rainfall data, soil moisture, which are obtained for point locations. SPI and EDI uses the precipitation data for the analysis, with a minimum of 30 years datasets. The rainfall data collected are discrete and are sparsely located. The other parameters such as vegetation, temperature and soil moisture are not taken into account by SPI and EDI. These parameter govern the response of the agriculture system to the water shortage. Thus, remote sensing based indices are more preferred for agricultural drought monitoring.

\subsection{Agricultural Drought Monitoring Using Remote Sensing Based Indices}

Out of the total damage caused by natural hazards, around $22 \%$ affects the agriculture sector (FAO, 2015). Drought is the largest natural hazard for agricultural sector causing $84 \%$ of losses to the sector out of losses due to all natural hazards (FAO, 2014). The limitations of traditional drought monitoring indices makes assessment and monitoring of agricultural drought a difficult task. Remote sensing based indices have opened up a new avenue for the assessment and monitoring of agricultural system. The remote sensing data obtained from various sources are processed and the indices like Normalized Difference Vegetation Index (NDVI), Vegetation condition index (VCI), Temperature condition Index (TCI), Vegetation Temperature Condition Index (VTCI), Shortwave Angle Slope Index (SASI), etc. are generated for assessment and monitoring of agriculture drought. While the NDVI and VCI are completely based on the vegetation, TCI takes into account the temperature factor and SASI accounts for the soil moisture part. In India, National Agricultural Drought Assessment and Monitoring System (NADAMS) uses SASI to characterize the Agricultural drought. NADAMS started its operations in 1990, and it works with providing information about severity, onset and persistence of agricultural drought at state, district and sub-district level using remote sensing and ground based inputs (Sai et al., 2016). The use of remote sensing data has many advantages like wide spatial coverage, repetitively in temporal domain and its cost effectiveness. Therefore, the remote sensing based techniques are efficient and accurate as compared to traditional methods for drought monitoring. The present study focuses on the comparison of meteorological based drought index like SPI and EDI to monitor drought and identify the severity, persistence and onset of drought. Analyze the agriculture drought using various remote sensing based indices and select the remote sensing based index for better drought characterization.

\section{MATERIALS AND METHODOLOGY}

\subsection{Study Area}

Maharashtra is the third largest state of India, with an area of $307,713 \mathrm{~km}^{2}$ divided into 35 districts. The state is bounded by Arabian Sea in the west, Chhattisgarh in east, Karnataka in south, Gujarat in northwest, Madhya Pradesh in northeast, Andhra Pradesh in southeast and Goa in south west. The geographical area is enclosed by North latitude $15^{\circ} 40^{\prime}$ and $22^{\circ} 00^{\prime}$ \& East Longitudes $72^{\circ} 30^{\prime}$ and $80^{\circ} 30^{\prime}$. The state has a population of around 11.2 billion, making it the second largest state in terms of population. Geographically, the state is divided into the Konkan coastal plains towards the west and Deccan Plateau towards the east by the Sahyadri hills which has an average elevation of 1200 metres. On the other hand, the Deccan plateau or the Western Ghats gives rise to the major south Indian rivers like Godavari and Krishna. The entire plateau is composed of rocks from diverse origin, which has undergone substantial amount of metamorphism. These ancient rocks mainly comprise of the Deccan traps, which covers up to $80 \%$ area of the state. The Deccan Plateau has black soil, which is rich in iron and moisture retentiveness but has less nitrogen and organic matter content. National Bureau of Soil Survey and Landuse Planning (NBSS\&LUP) has broadly classified the soil of the state into four groups, which are Soil of Konkan coast, Soil of Western Ghats, Soil of the Upper Maharashtra, Soil of Lower Maharashtra. The climate of Maharashtra varies between heavy monsoon showers to hot summers. Physiography and location govern the type of climate prevailing in an area, the coastal region receives heavy monsoon while it decreases as we proceed towards the east. The annual rainfall reaches a maximum of around $6000 \mathrm{~mm}$ in Ghats and decreases to the east to reach a level of below $500 \mathrm{~mm}$. It further increases in the east to reach a second peak of $1500 \mathrm{~mm}$. The temperature in the state varies between a maximum in the range of $27^{\circ} \mathrm{C}$ and $40^{\circ} \mathrm{C}$ to a minimum temperature in range $14^{\circ} \mathrm{C}$ and $27^{\circ} \mathrm{C}$. Based on vegetation, soil and rainfall, the state has been divided into 9 agro climatic zones which are South Konkan Coastal Zone, North Konkan Coastal Zone, Western Ghats, Transitions Zone-1, Transition Zone-2, Scarcity Zone, Assured Rainfall Zone, Moderate Rainfall Zone, and Eastern Vidharbha Zone. Agriculture is of immense importance for the state of Maharashtra. Around $61 \%$ of the total population of the state depends on agriculture directly or indirectly. Jowar, Pulses, Rice, Sugarcane, Bajra, Turmeric, Cotton, oil seeds like Sunflower, Groundnut and Soyabean are the major crops cultivated. Grapes, Oranges, Mangos, and Bananas account for the fruits cultivated in the state. Out of the total 226.1 lakh ha area under cultivation, 33.5 lakh ha area is under irrigation. This 
proves that majority of the agricultural is rainfed. The scarce and inadequate rainfall causes these areas to be severely drought hit, thus around $24 \%$ of country's drought prone area lays in the state.

\subsection{Datasets Used}

The study uses meteorological, remote sensing and ancillary datasets. The meteorological datasets include the grid wise precipitation data obtained from India Meteorological Department (IMD), which has a spatial resolution of 0.25 degree. The data from 1901 to 2015 has been extracted grid wise for around 500 grids for whole state of Maharashtra.
The remote sensing based datasets where used for the computation of remote sensing based indices. The Moderate Resolution Imaging Spectroradiometer (MODIS) based Normalized Difference Vegetation Index (NDVI), Land Surface Temperature (LST), Enhanced Vegetation Index (EVI), Reflectance data and Land use land cover (LULC) datasets were obtained from U.S Land Processes Distributed Active Archive Center (LPDAAC) (http://lpdaac.usgs.gov).

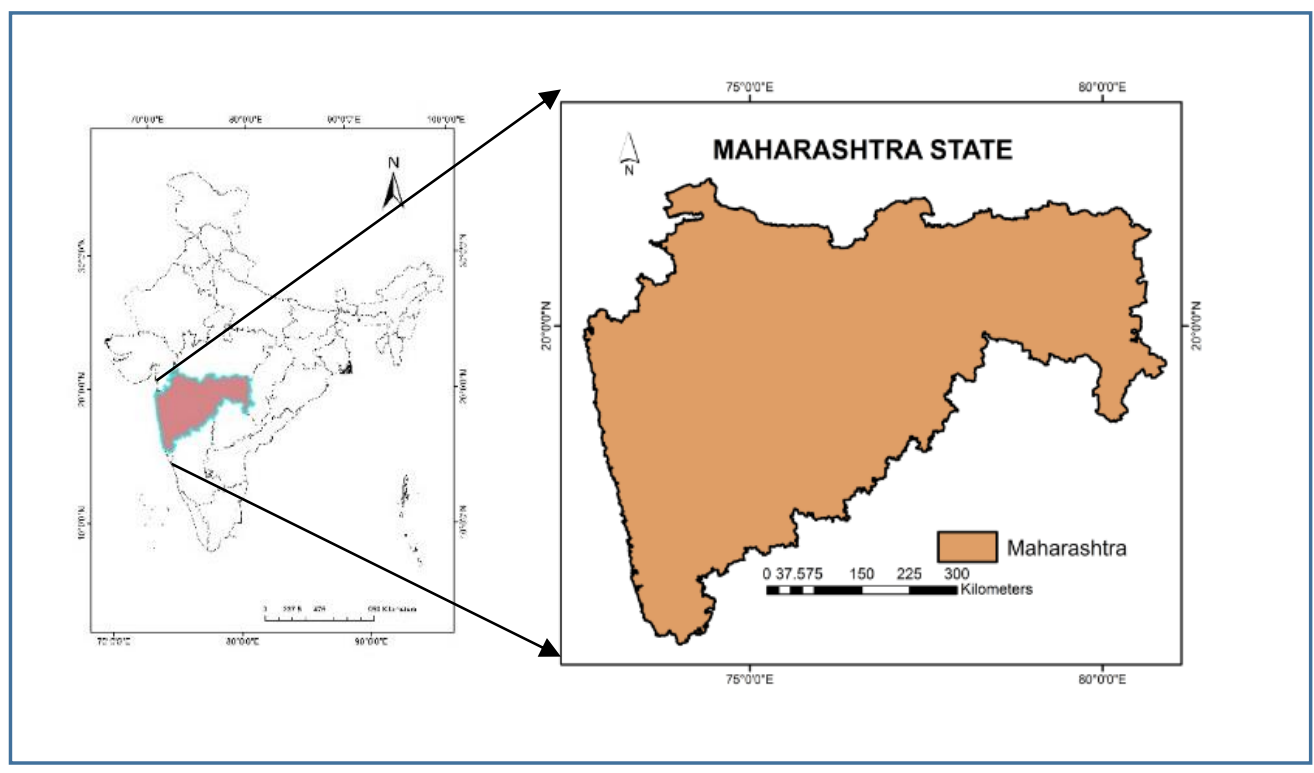

Figure 1. Study Area - Maharashtra State

- MOD13A2: The MODIS 16 day $1 \mathrm{~km}$ NDVI and EVI product.

- MOD11A2: The MODIS 8 day $1 \mathrm{Km}$ LST product.

- MOD09GA: MODIS Reflectance comprises of sevenband product, which are derived from MODIS Level 1B land bands. The seven bands include band1 (620$670 \mathrm{~mm})$, band 2 (841-876nm), band3 (459-479nm), band4 $(545-565 \mathrm{~nm})$, band5 (130-1250nm), band6 $(1628-1652 \mathrm{~nm})$, and band7 $(2105-2155 \mathrm{~nm})$. These are $500 \mathrm{~m}$ spatial resolution, daily datasets.

- MCD12Q1: The MODIS Land Cover Product provides information about five global land cover classification systems. Yearly land use land cover data at a spatial resolution of $500 \mathrm{~m}$.

The ancillary datasets used includes the agro-ecological boundary map from the NBSS \& LUP, the administrative boundary map from Survey of India (SOI).

\subsection{Methodology}

The methodology constitutes of two sections: The meteorological drought assessment and the remote sensing based drought assessment. The meteorological part involves the calculation of two meteorological drought indices namely Standard Precipitation Index (SPI) and the Effective Drought Index (EDI). The agricultural drought is monitored using the remote sensing based indices. The remote sensing (RS) indices used in the study are Vegetation Condition Index (VCI), Temperature Condition Index (TCI), Vegetation Health Index (VHI), and Shortwave Angle Slope Index (SASI). The comparison between different RS based indices was carried out to identify the best suitable index for the study area. 


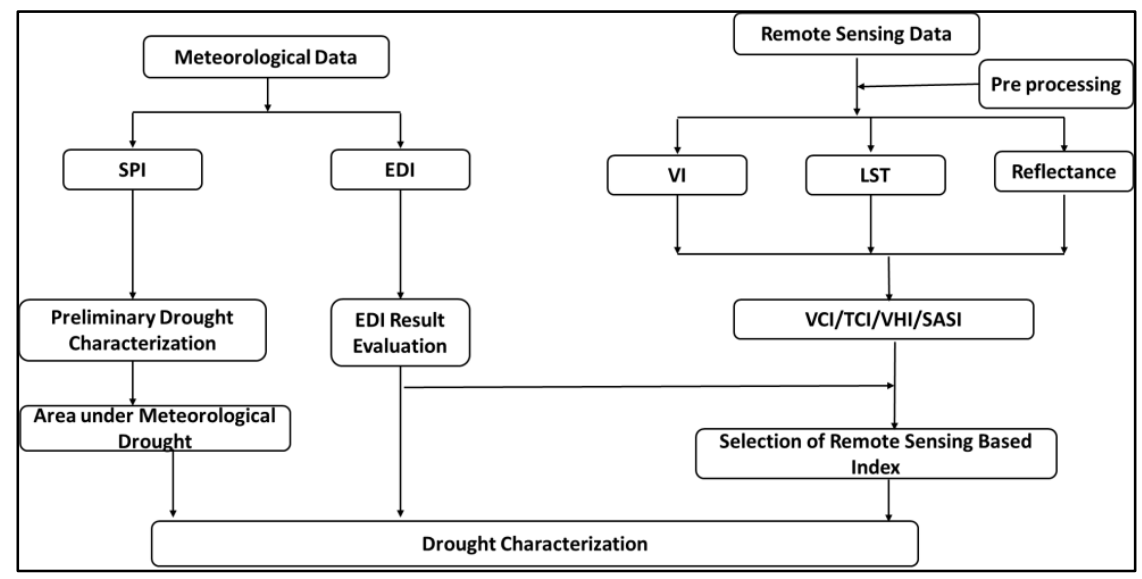

Figure 2. Flowchart of Methodology

\subsubsection{Meteorological drought monitoring:}

Meteorological drought monitoring can be accomplished by using various meteorological indices like Rainfall Anomaly Index (RAI), Percent of Normal, SPI, EDI, Reconnaissance Drought Index (RDI), etc. In the present study, the meteorological drought monitoring has been carried out by using SPI and EDI due to their wide acceptance and intercomparability.

The meteorological drought index, SPI, was calculated for 115 years from 1901 to 2015 using gridded rainfall data for over 499 grids covering entire state. Initially SPI computation involves the determination of probability density function, which explains the long-term time series of precipitation data. This is followed by the estimation of cumulative probability. The inverse normal function with mean zero and variance one is applied to cumulative probability function to obtain the required SPI values (Guttman, 1999). SPI computation involves fitting the rainfall values to the gamma distribution by using the following equations.

$\mathrm{G}(\mathrm{x})=\frac{\int_{0}^{x} x^{\alpha-1} e^{-x / \beta} \mathrm{dx}}{\beta^{\alpha} \Gamma \alpha}$

where $\alpha>0, \alpha$ is a shape factor, $\beta>0, \beta$ is the scale factor and $\mathrm{x}$ represents the precipitation data.

$\Gamma(\alpha)=\int_{0}^{\infty} y^{\alpha-1} e^{-y} d t$ where, $\Gamma(\alpha)$ is the gamma function.

Shape parameter $=\beta=\frac{1+\sqrt{ }\left(1+\frac{4 U}{3}\right)}{4 U}, A=\ln x-\frac{\Sigma \ln (X i)}{N}$

Scale parameter $=\alpha=\frac{x}{\beta}$

where, $X i$ represents all non-zero precipitation values and $N$ is the number of non-zero precipitation values. The value of $A$ is obtained by subtracting the log of all precipitation data from the $\log$ of mean of all rainfall amount. The scale parameter and shape parameter can be calculated from the equation 3 and 4 (Shah et al., 2015). For zero values of precipitation, the gamma function is not defined, to incorporate those values. The cumulative probability is modified by the given formula.

$H(x)=q+(1-q) G(x)$

In Equation 5, the probability of a zero rainfall is denoted by q. If the number of zero rainfall values is represented by $m$, then $q$ can be estimated by $m / n$.

The cumulative probability $H(x)$ is then converted to SPI values by converting them into standard normal random variable $(Z)$. Based on the $Z$ values, the area can be classified as wet and dry, as positive SPI indicate wetness and negative SPI values indicate dryness (Shah et al., 2015)

\begin{tabular}{|c|c|}
\hline SPI Range & Category \\
\hline+2 or more & Extremely Wet \\
\hline 1.55 to 1.99 & Very Wet \\
\hline 1.0 to 1.49 & Moderately Wet \\
\hline-0.99 to 0.99 & Near Normal \\
\hline-1.0 to -1.49 & Moderately Dry \\
\hline-1.5 to -1.99 & Severly Dry \\
\hline-2 or less & Extremely Dry \\
\hline
\end{tabular}

Table 1.Standard Precipitation Index 
The number of drought that has occurred in the past 115 years from 1901 to 2015 was plotted .The severity and persistence of drought was plotted, thus evaluating the severe most drought that has longest persistence in the past 115 years. The SPI values were interpolated using inverse distance weightage method and the maps were generated for the year 2000 to 2015. The drought and non-drought year were identified from the SPI values, the interpolated maps were reclassified based on the SPI values, to severely drought prone, moderately drought, near normal, etc.

Another meteorological drought index, Effective Drought Index (EDI), was computed on 16 daily basis for a period of 115 years from 1901 to 2015 . The water accumulated from rainfall is considered as a function of time in EDI computation (Byun and Kim, 2010). Calculation of Effective Precipitation (EP) is the initial step. EP represents the effect of rainfall, which occurred many days prior. In this research, the effect of rainfall 15 days before the interpolation, which were further reclassified based on the severity of drought. The area under drought determined by EDI and SPI were analyzed for different ecological zones to identify the merits and demerits of each index in drought characterization.

\subsubsection{Remote sensing based drought monitoring}

The remote sensing based drought monitoring has advantages like near real time monitoring at low cost with very less input of time and labor. The preprocessing of remote sensing datasets include the following

- Conversion of HDF file to TIFF formats

- Mosaicking ,clipping, and re-projecting

- Scaling-The scaling factor of LST, NDVI and Reflectance data are $0.02,0.0001,0.0001$ respectively.

- Masking-The MODIS LULC was used to map out the agricultural areas and cloud masking was also carried out.

The remote sensing indices VCI, TCI, VHI and SASI were computed. Agriculture drought is always marked by a decrease in amount of vegetation in fields (Tsiros et al., 2004). This can be easily identified using VCI as it depend completely on NDVI. The process of normalization is used to identify the drought and non-drought pixels (Quiring and Ganesh, 2010). The maximum and minimum NDVI values denoted by 100 and 0 are linearly scaled (Kogan, 1995). The VCI values also ranges from 0 to 100 depending upon the absence or presence of vegetation in field.

$\mathrm{VCI}=100 *\left(N D V I-N D V I_{\min }\right) /\left(N D V I_{\max }-N D V I_{\min }\right)$

In Equation 9, $\mathrm{NDVI}_{\min }, \mathrm{NDVI}_{\max }$ represents the multiyear maximum and minimum values of NDVI.

VCI has very low value in case of high cloud cover, thus wrongly depicting them as drought prone areas. To overcome such problems the temperature-based indices can be used, which uses the thermal band derived brightness values to compute TCI. Its values ranges from 0 to 100 , a existing day is considered. The basic equation for EDI calculation is given below

$$
\begin{aligned}
& \mathrm{EP}_{15}=\sum_{n-1}^{15}\left[\left(\sum_{m-1}^{n} P m\right) / n\right] \\
& \mathrm{DEP}_{15}=\mathrm{EP}_{15}-\mathrm{MEP}_{15} \\
& \mathrm{EDI}_{15}=\mathrm{DEP}_{15} / \mathrm{SD}\left(\mathrm{DEP}_{15}\right)
\end{aligned}
$$

$E P_{15}$ defines the effective precipitation of a definite day, accumulated for 15 days. $P_{m}$ is rainfall amount of a day $\mathrm{m}$ days prior to the specific day. $D E P_{15}$ is the difference between the $E P_{15}$ and the mean of $E_{15}$ (MEP), SD (DEP 15$)$ is the standard deviation of the $D E P_{15}$ (Byun and Wilhite, 1999). The EDI was computed for a time period of 1901 to 2015 for the whole state of Maharashtra. The map of EDI was composed for the years 2000 to 2015 , using IDW

higher value suggest drought while the lower values indicate non drought areas (Kogan, 1995).

$\mathrm{TCI}=100 *\left(B T_{\max }-B T\right) /\left(B T_{\max }-B T_{\min }\right)$

where $\mathrm{BT}, \mathrm{BT}_{\max }, \mathrm{BT}_{\min }$ are multiyear maximum and minimum of brightness temperature.

An integrated approach of using both LST and NDVI, counters the limitation of individual indices. VHI can be computed using the formula given below.

$\mathrm{VHI}=\mathrm{a}$ VCI $+(1-\mathrm{a}) \mathrm{TCI}$

where the value of ' $a$ ' denotes the weight constant for $\mathrm{VCI}$, which shows the contribution of VCI in the calculation of VHI. The value of ' $a$ ' depends on the contributions of moisture and temperature during a vegetation cycle. It is generally assumed to have equal weightage, as it is difficult to determine it.

As far as agricultural drought is concerned, the soil moisture is an important parameter. The above mentioned indices does not take care of soil moisture while identifying drought in an area. Palacios-Orueta et al. (2006) used an index SASI, which incorporates the effect of soil moisture in the drought measurement. SASI measures the angle formed between the bands NIR, SWIR1, SWIR2 of central wavelengths $858 \mathrm{~mm}, 1240 \mathrm{~mm}, 1640 \mathrm{~mm}$ respectively. SASI has the capability of differentiating the dry and wet soil and the healthy and sparse vegetation (Das and Murthy, 2013). As compared to other indices, SASI depends on the inert band relationships and the angle formed between them. The inclusion of two SWIR bands makes SASI more sensitive to soil moisture. SASI values varies from positive to negative as the soil condition shifts from dry to wet.

SASI computation involves the following steps:

$$
\begin{aligned}
& \beta_{\text {SWIR } 1}=\cos ^{-1}\left[\left(a^{2}+b^{2}+c^{2}\right) /(2 * a * b)\right] \\
& \text { Slope }=\left(R_{\text {SWIR } \left.2-R_{\text {NIR }}\right)}\right. \\
& \text { SASI }=\beta \text { SWIR } 1 * \text { Slope (radians })
\end{aligned}
$$


where, $a, b$ and $c$ represents the Euclidian distances between the vertices NIR and SWIR1, SWIR1 and SWIR2, and NIR and SWIR2, respectively. The value of angle $\beta_{\text {SwIR1 varies from large to small as the soil moisture shifts }}$ dry to moist (Khanna et al., 2007). A high positive value of SASI is representative of a dry soil while a high negative SASI value indicates healthy vegetation (Das and Murthy, 2013).

\section{RESULTS AND DISCUSSION}

\subsection{Meteorological Drought in Maharashtra}

Two meteorological drought indices namely SPI and EDI were used to identify the meteorological drought in the Maharashtra state. The gridded rainfall data from 1901 to 2015 were used calculating SPI and EDI. The EDI values for the time period 2000-2015 were used further for the comparison with remote sensing based indices. The drought and non-drought years for this time period were also identified for the comparison.

The severity and persistence of drought were analyzed grid wise for different districts. The severity of drought represents the intensity of drought, while the persistence shows how long the drought prolonged. The grid wise plots of severity and persistence were created. The Figures $3 \& 4$ shows the number of drought that has occurred for the grid
The area under drought as estimated by different drought indices were identified and these results were compared with the area under drought as per EDI. The comparison was carried out to identify the best remote sensing index for assessment and monitoring of agricultural drought.

$164(18.83 \mathrm{~N}, 76.108 \mathrm{E})$ and grid $166(18.83 \mathrm{~N}, 76.108 \mathrm{E})$, both these grids represent are covered by drought prone Beed District. It is observed from Figure 3 that a maximum of four drought have occurred in a year $(1951,1954,1960$, 1962 ) in the grid 164 and in grid 166 maximum of 5 drought have occurred in a year (1973). Figure 5 and 6 shows the plot of drought persistence for grid $164(18.83 \mathrm{~N}$, $76.108 \mathrm{E})$ and $166(18.83 \mathrm{~N}, 76.108 \mathrm{E})$, respectively. The severity persistence graph for the grid $164(18.83 \mathrm{~N}$, $76.108 \mathrm{E})$ and $166(18.83 \mathrm{~N}, 76.108 \mathrm{E})$ are shown in Figures 7 and 8. Drought, which has persisted for 7 months, has occurred in the years 1972, 1985, 2003 in figure 5. The Figure 7 , it can be seen that the drought of severity -0.4 and -1.5 persisted for 1 month, 7 month respectively.

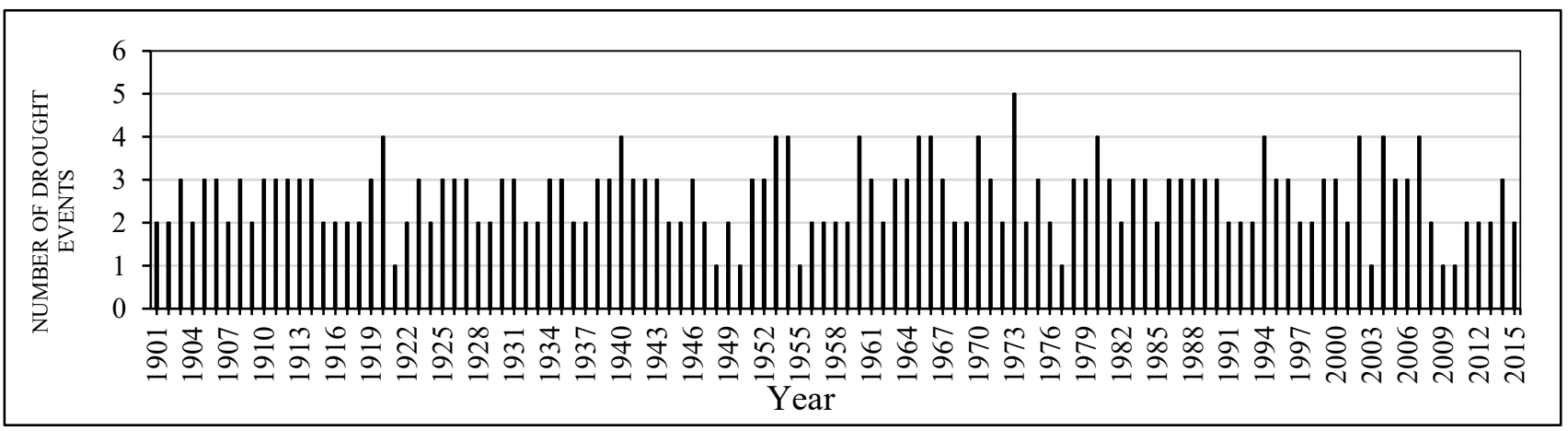

Figure 3.Graph Showing Number of Drought Occurred in Grid Number 164 (18.83N,76.108E)

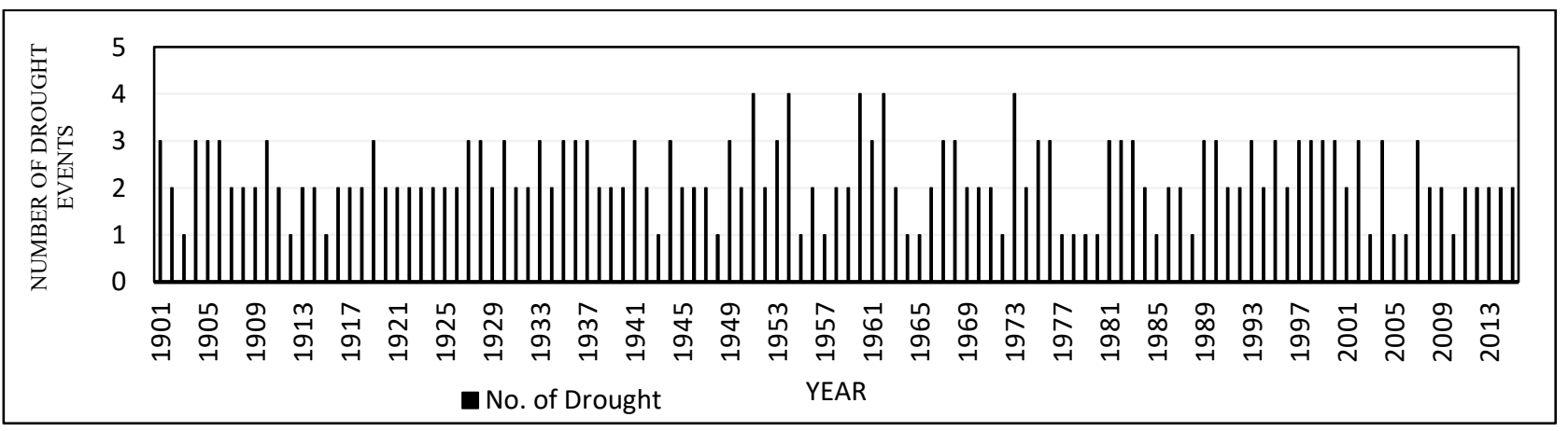

Figure 4.Graph Showing Number of Drought Occurred in Grid Number 166 (18.83N,76.108E) 


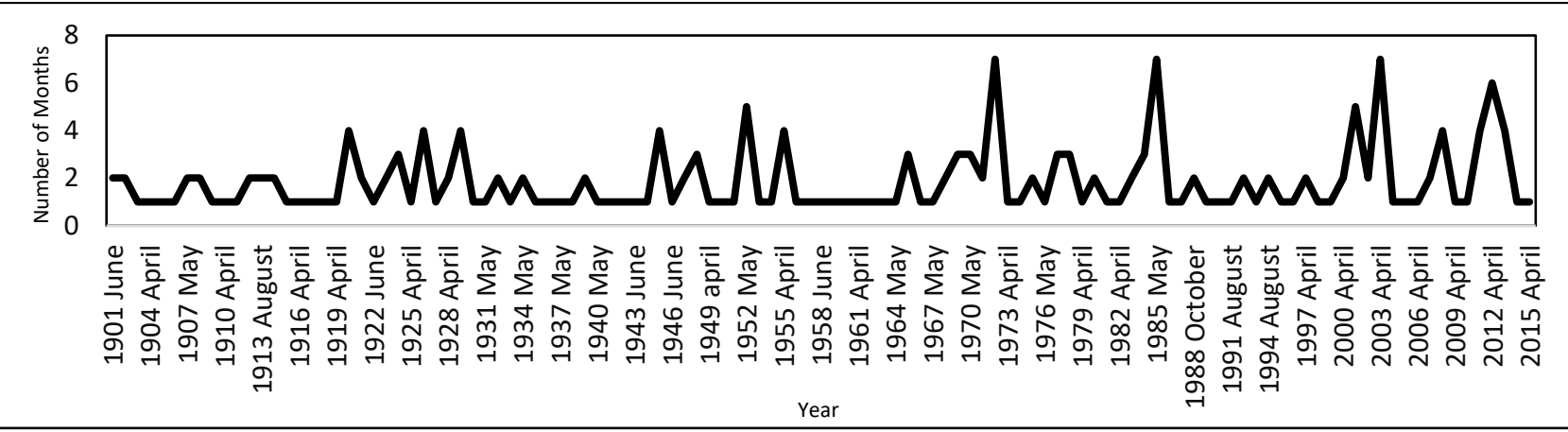

Figure 5.Graph showing persistence of drought in grid $164(18.83 \mathrm{~N}, 76.108 \mathrm{E})$

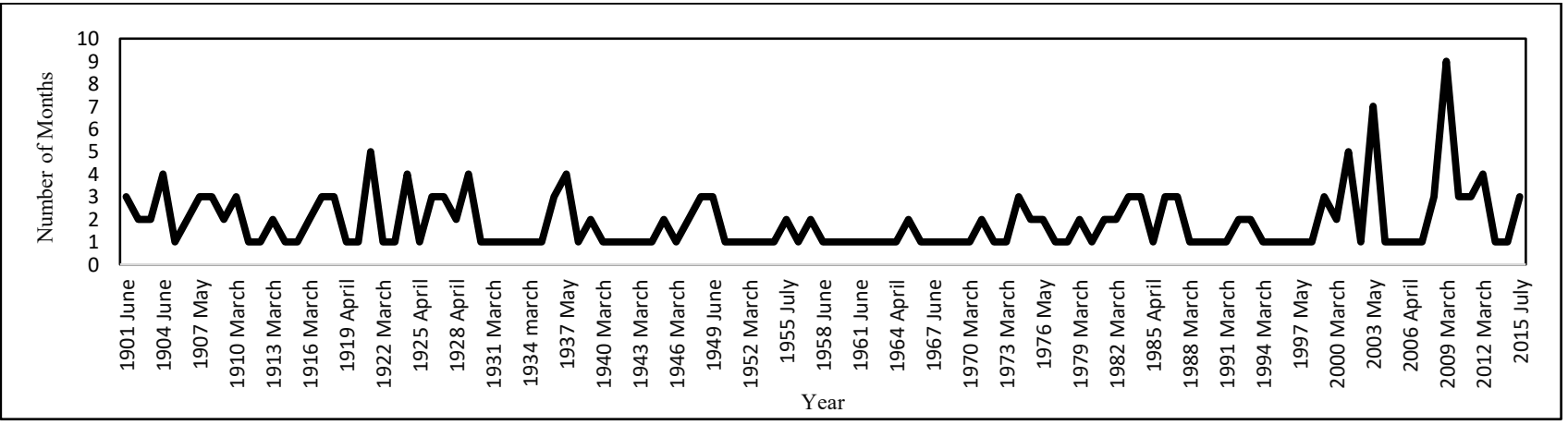

Figure 6.Graph showing persistence of drought in grid $166(18.83 \mathrm{~N}, 76.108)$

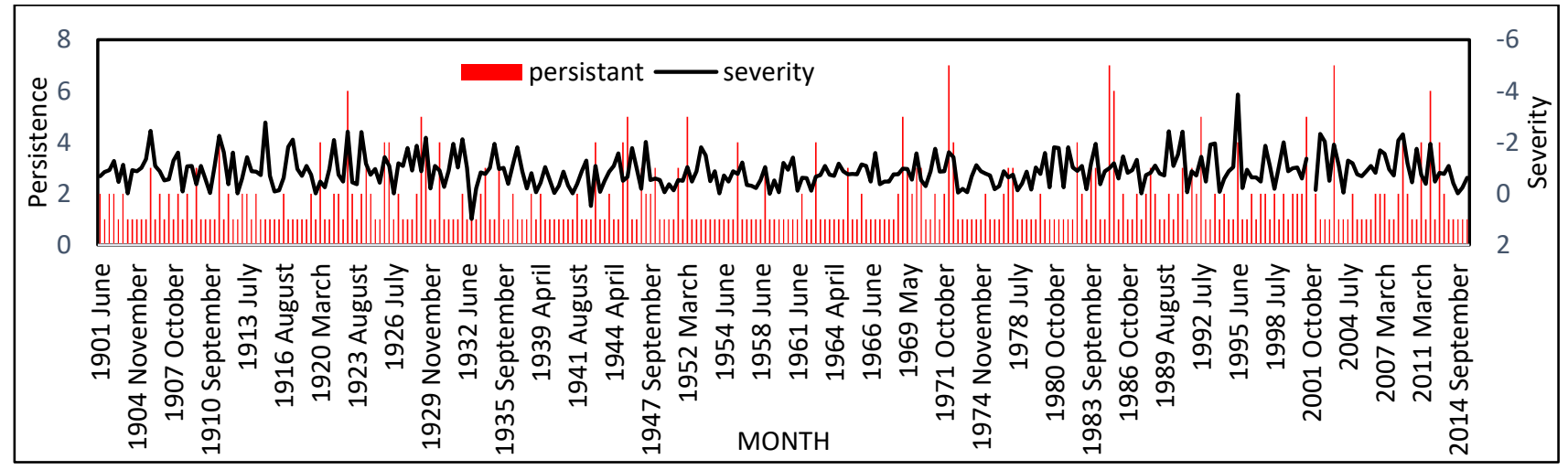

Figure 7.Persistence Severity Graph for the grid $166(18.83 \mathrm{~N}, 76.108)$

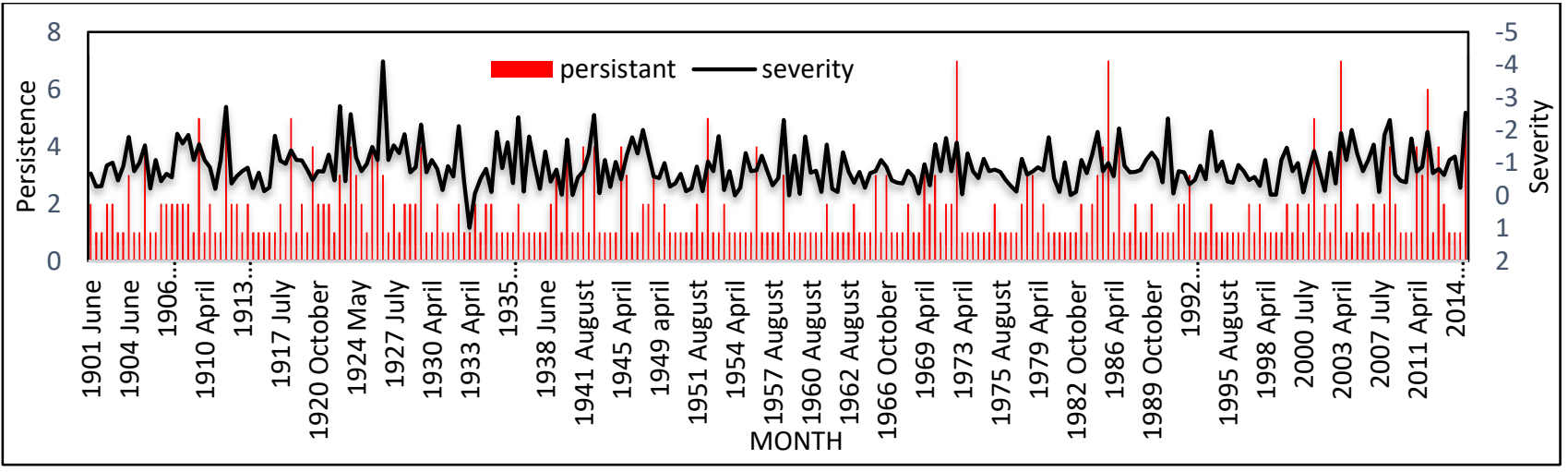

Figure 8.Persistence Severity Graph for the grid 164(18.83N, 76.108E) 


\subsubsection{Meteorological drought monitoring using SPI}

The SPI was calculated for the years 1901 to 2015, while the SPI based drought area mapping was carried out for the years 2000-2015, by generating 192 SPI maps using the Inverse Distance Weightage (IDW) method. The indentified drought years using these SPI maps are 2000, 2002, 2007, 2009, 2011, 2014 and 2015. Figure 9 shows the interpolated maps for selected month of the years 2001, 2002, 2009 .

\subsubsection{EDI based meteorological drought monitoring}

EDI maps were composed for a time period of 16 years from 2000-2015. EDI were calculated on 16 daily basis and total 384 EDI maps were generated using IDW interpolation technique. It is observed that EDI has an advantage of identifying the sub-monthly drought. SPI was unable to identify the drought, which occurred for a time period of less than a month. As SPI uses the total monthly rainfall, if a rainfall deficit occurs in the first fortnight and a rainfall excess occurs in the second fortnight, SPI will not be able to account for the rainfall deficit, which has occurred in the first fortnight.

When it comes to agricultural drought, the unnoticed drought in the first fortnight can lead to a decrease in production. This will drastically affect the yield. Therefore, sub-monthly scale of monitoring is very much crucial as far as agricultural drought is considered. Figures 10 (a) \& (b) show the interpolated EDI maps. As it can be seen for April 2008, the first fortnight has very less area under drought, but the second fortnight shows more area under drought. The use of EDI helps in identifying the submonthly drought which has occurred in the second fortnight.
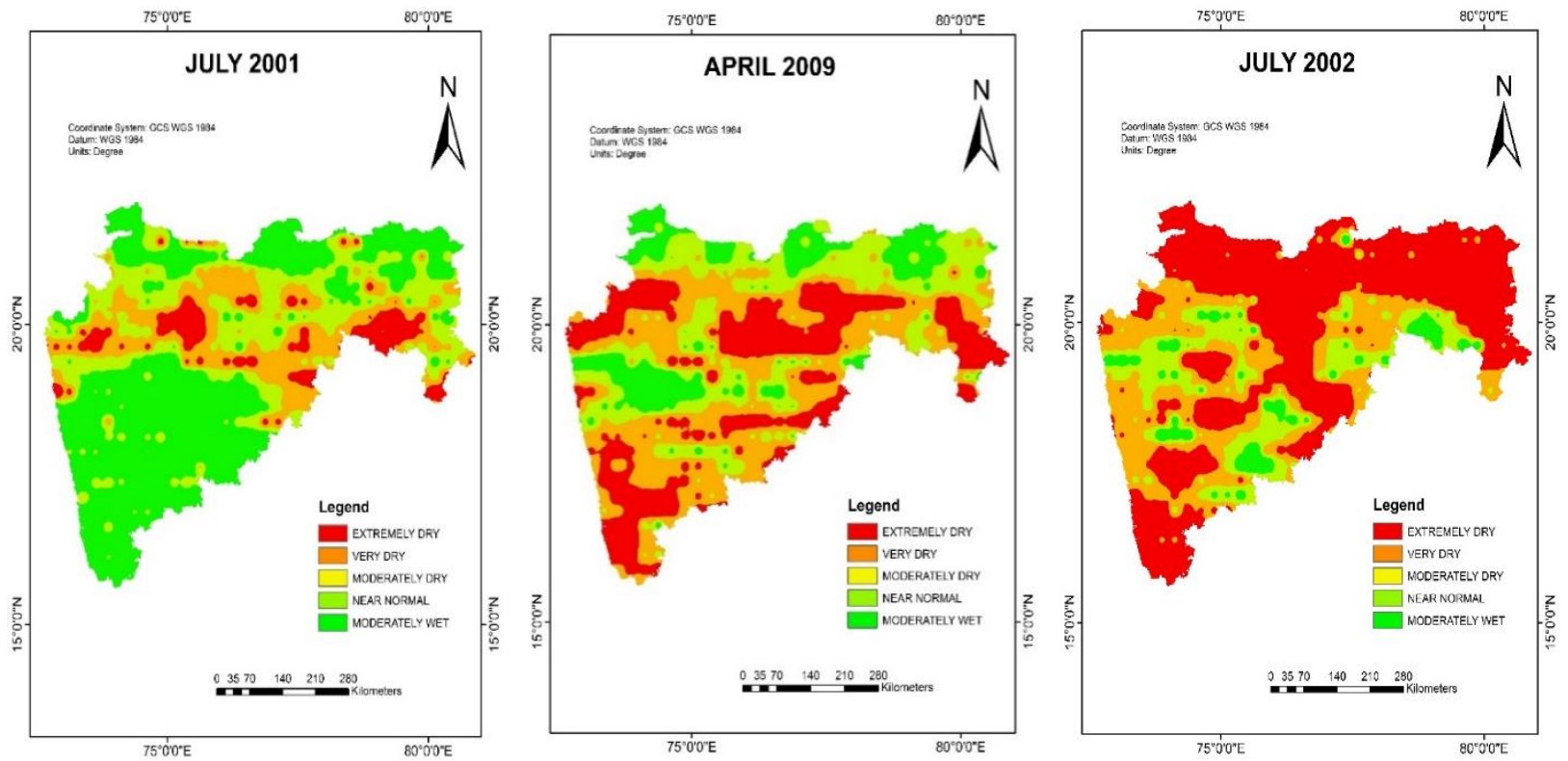

Figure 9. Interpolated SPI maps of July 2001, April 2009, and July 2002
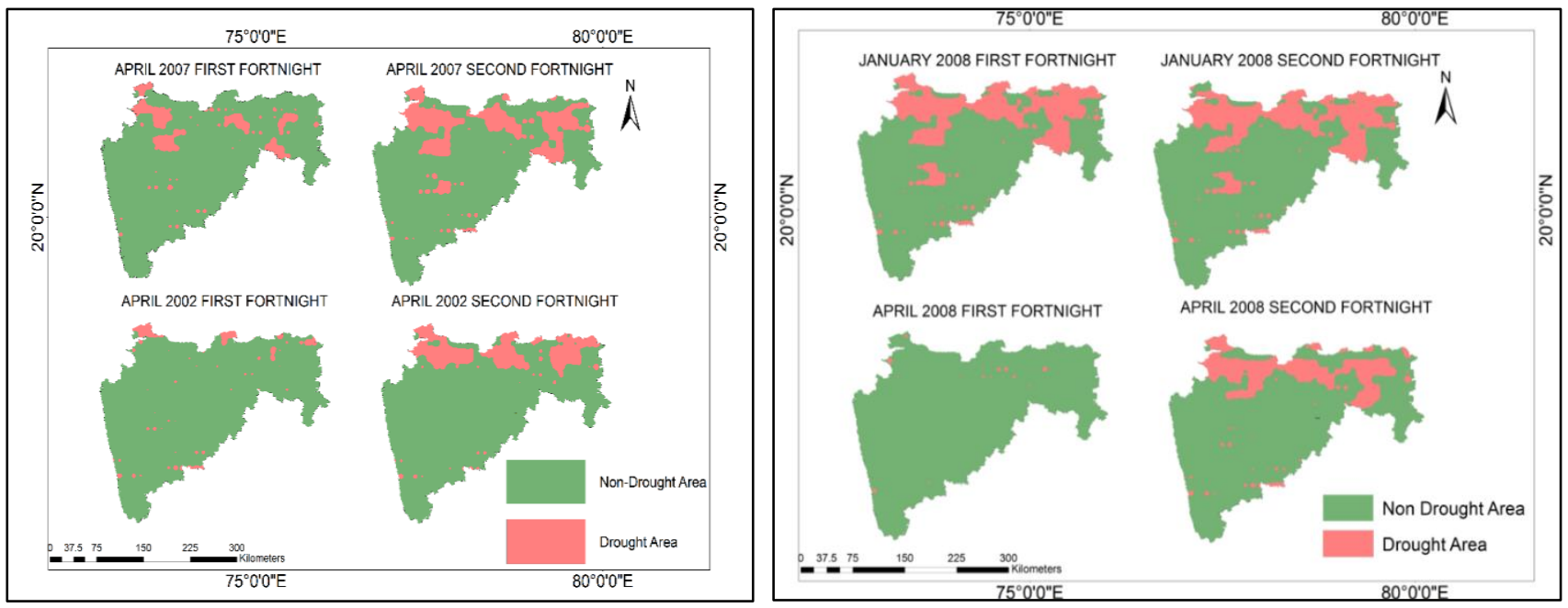

Figure 10 (a).Interpolated EDI maps for the year 2007 and 2002 (b)Interpolated EDI map for the year 2008 


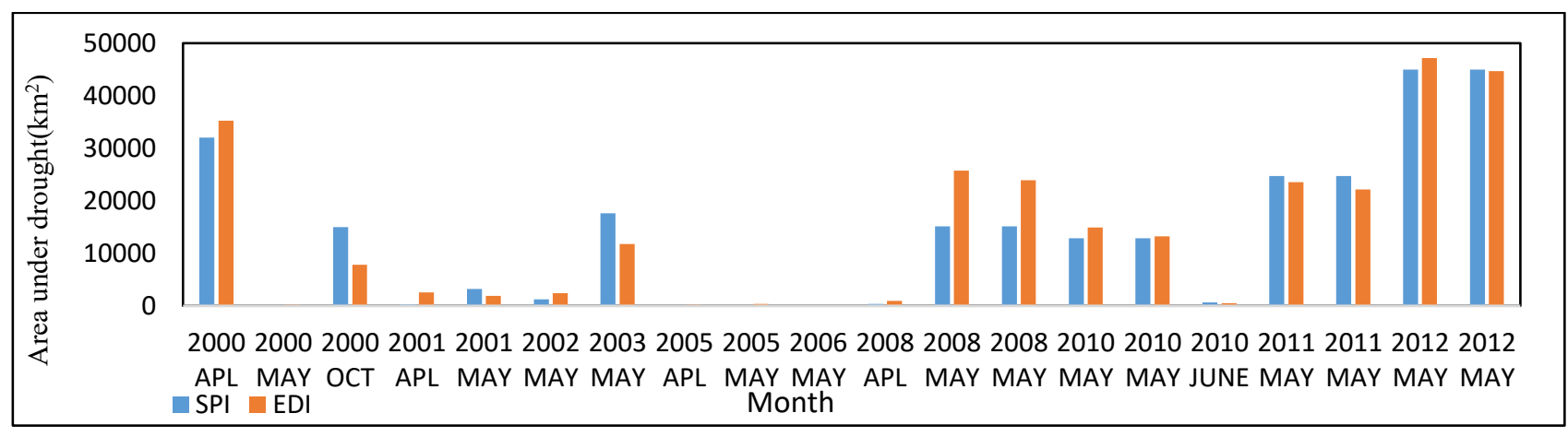

Figure 11.Area under drought as per SPI and EDI for Deccan Plateau

\subsubsection{Comparison of SPI and EDI}

The area under drought as obtained from EDI and SPI were compared with each other for different ecological zones. The comparison of SPI and EDI can give three kinds of observations. Firstly, when both SPI and EDI shows drought, the observaions of these kind are plotted in the Figure 11. As it can be seen that in April 2000, October 2000, May 2010, May 2011 and May 2012, the area under drought as per SPI and EDI is same. Secondly, when it is a drought as per SPI while either of the EDI values disagree

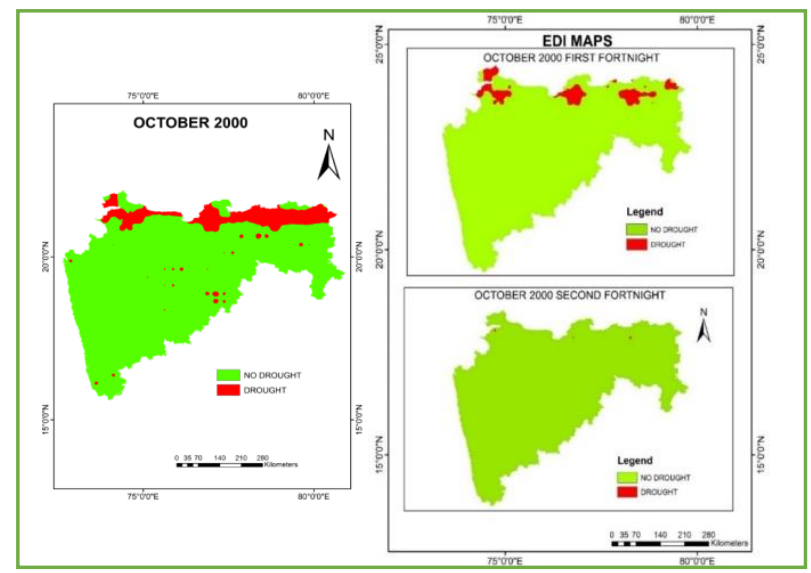

Figure 12. SPI map of October 2000 was compared with EDI maps of October 2000 first second fortnight

\subsection{Remote Sensing Based Agricultural Drought Monitoring}

Remote sensing based indices like VCI, TCI, VHI and SASI were used for the agricultural drought monitoring. The indices were calculated on 16 daily basis for the period of 2000 to 2015 at a spatial resolution of $1 \mathrm{~km}$. A total of 368 maps were composed for the time period of 2000-2015 by each index. Figure 14(a)shows the VCI maps for the year 2002, 2010. As it can be seen that the area under drought is more in January 2002 as compared to January2010. Similar observations could be seen in the TCI or vice-versa. The Figure 12 shows this case, where those areas that are marked as drought by SPI are not under drought in one of the fortnights. These differences have occurred in those areas, which are brightened areas in the XOR map shown in Figure 13. It was found that for grid $412(20.84 \mathrm{~N}, 78.826 \mathrm{E})$, which belongs to the brightened area, first fortnightly rainfall is $0 \mathrm{~mm}$ and for the second fortnight, the rainfall is $135.58 \mathrm{~mm}$. Thus, the sub-monthly drought could not be mapped by SPI while EDI could effectively identify that.

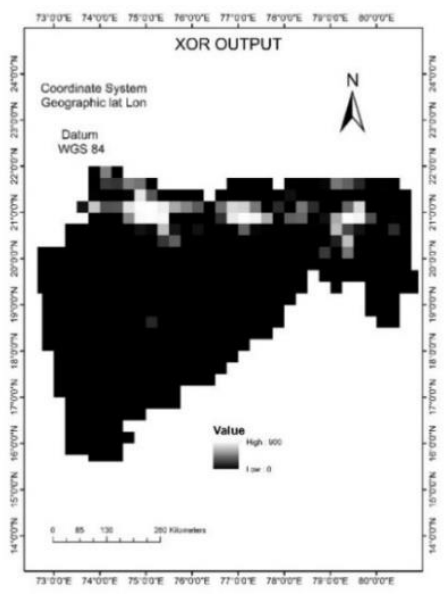

Figure 13.XOR Map

maps shown in the Figure 14(b). The VHI maps (Figure 14(c)) also have more area under drought in January 2002 as compared to others. The Figure 14(d) shows the area under drought from SASI. It can be seen that more area under dry vegetation is seen in year 2002 as compared to other years. The area under drought was calculated for drought and non-drought years separately. These results were compared with that of meteorological drought results, in order to obtain the best suited remote sensing index. The area under drought for months October and February was plotted for drought year (2002) and non-drought year (2010) respectively. 
ISPRS Annals of the Photogrammetry, Remote Sensing and Spatial Information Sciences, Volume IV-5, 2018 ISPRS TC V Mid-term Symposium “Geospatial Technology - Pixel to People”, 20-23 November 2018, Dehradun, India
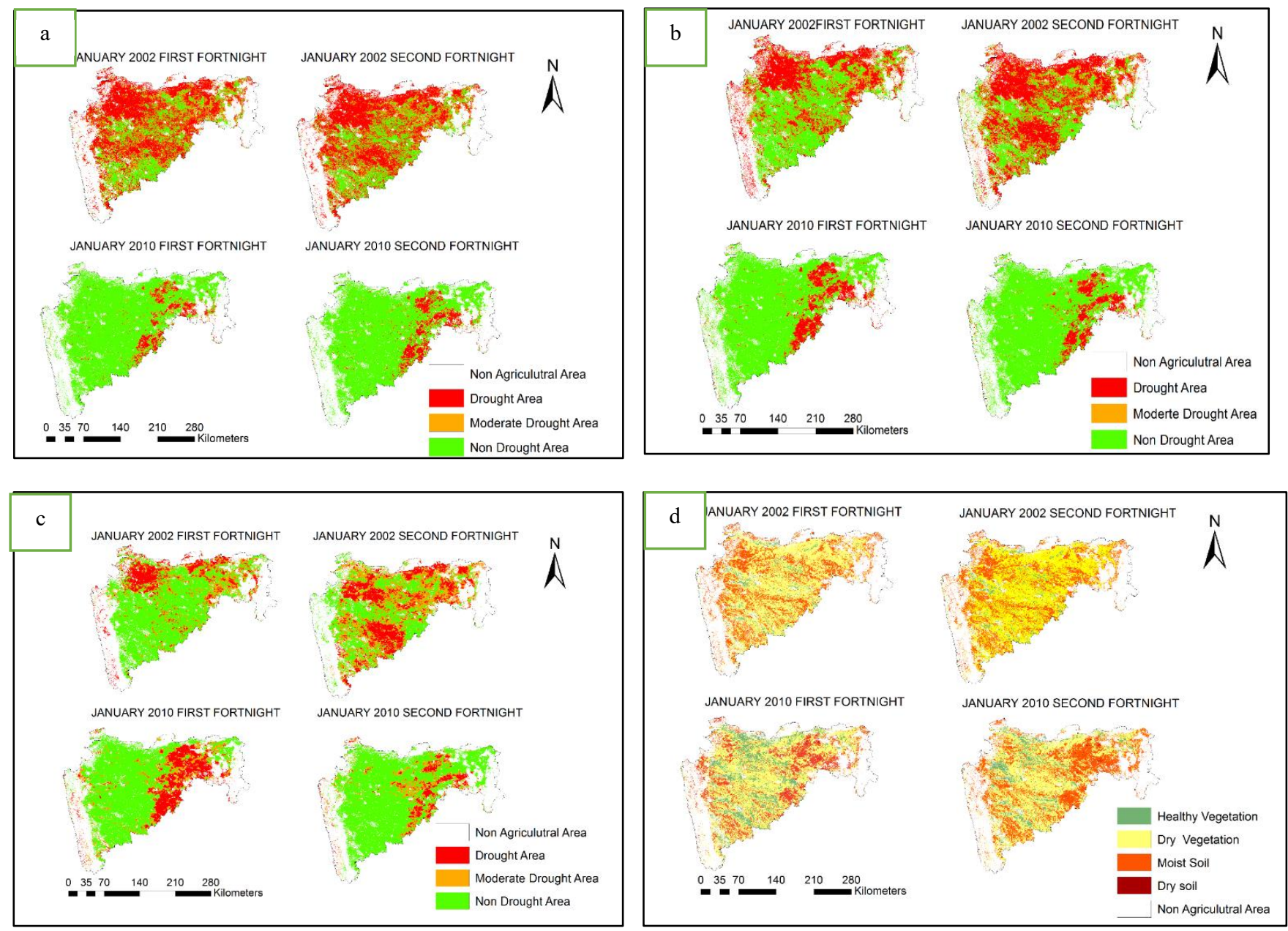

Figure 14(a).VCI maps for the year 2002 and 2010 (b)TCI maps for the year 2002 and 2010 (c)VHI maps for the year 2002 and 2010 (d) SASI maps for the year 2002 and 2010

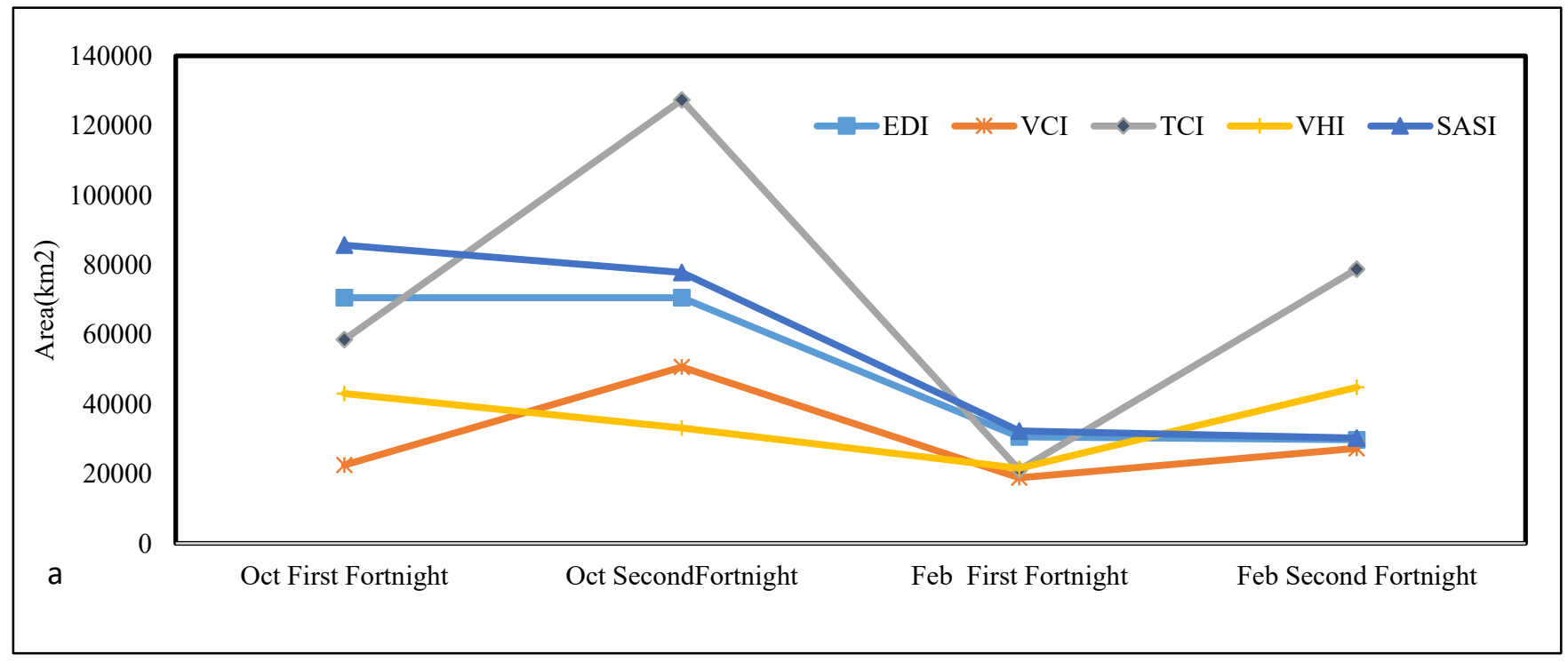

This contribution has been peer-reviewed. The double-blind peer-review was conducted on the basis of the full paper. https://doi.org/10.5194/isprs-annals-IV-5-253-2018 | @ Authors 2018. CC BY 4.0 License. 


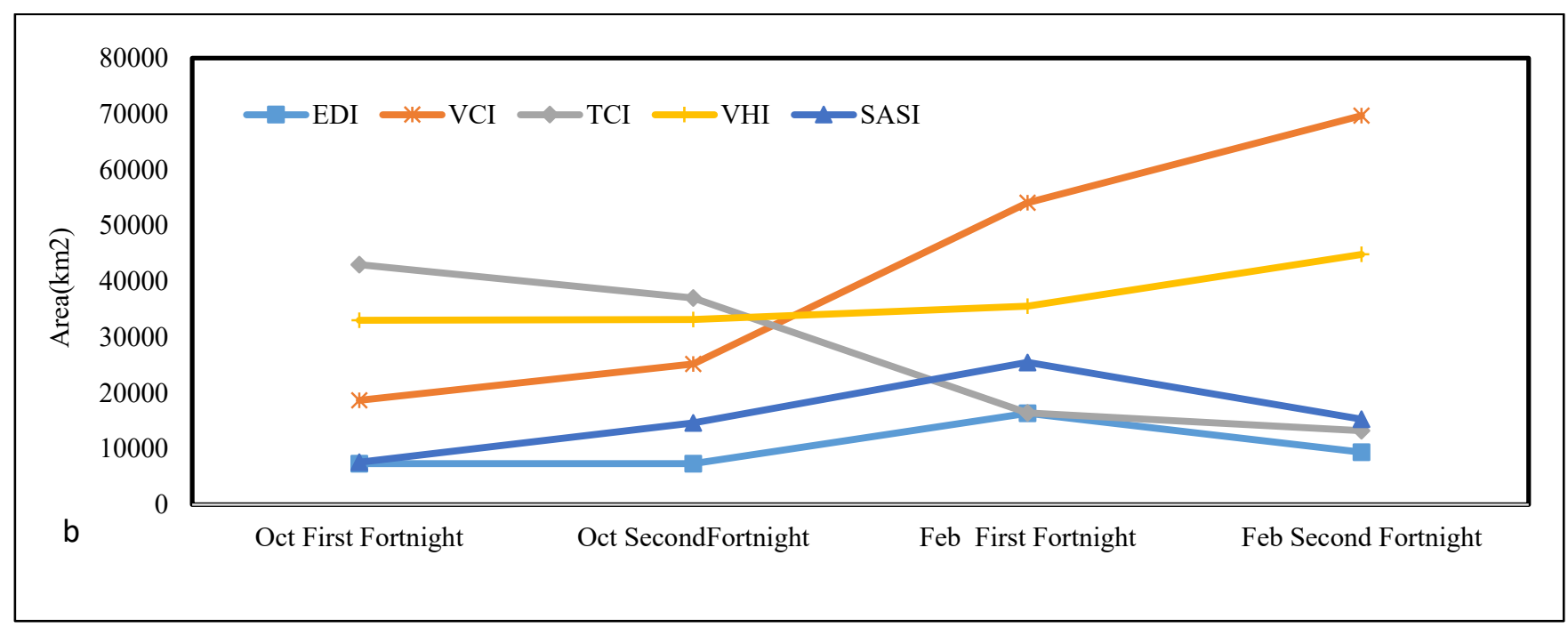

Figure 15.Area under drought as observed by different indices for year (a) 2002, and (b) 2010

As it can be seen from these graphs that the area under drought obtained by using EDI matches well with that of the area obtained using SASI. This shows that SASI has an advantage over other indices. SASI discriminates between the dry and wet soil as well as the dry and moist vegetation too. VCI and TCI on the other hand over predicts the area under drought. The comparison was done for drought year, 2002 and non-drought year 2010. For the year 2002, 41\% of the state area was under drought as per TCI, while as per SASI and EDI, it was around $22.9 \%$ and $27.8 \%$ respectively for the October first fortnight. For the nondrought year 2010, VCI predicted $22.64 \%$ drought area in the state, while as per EDI and SASI around 3\% and 4.9\% area was under drought. Figures15 (a) and (b) show the comparison of area under drought as per various remote sensing indices and EDI for the year 2002 and 2010.This shows that the results of EDI and SASI are comparable.

\section{CONCLUSIONS}

The objective of the work was to study the meteorological and agricultural drought by using meteorological indices and remote sensing based indices respectively. The initial

\section{REFERENCES}

Byun, H.R., \& Kim, D.W. (2010). Comparing the Effective Drought Index and the Standardized Precipitation Index. Options Méditerranéennes, A, 95, 85-89.

Byun, Hi Ryong, \& Wilhite, D. A. (1999). Objective quantification of drought severity and duration. American Meteorological Society, 12, 2747-2756.

Das, P. K. and Murthy, S. C. (2013) 'Early-season agricultural drought: detection, assessment and monitoring part focused on meteorological drought analysis using two indices namely Standard Precipitation Index and Effective Drought Index. The severity, persistence of meteorological drought was analyzed using SPI. The number of meteorological drought that has occurred in the state during the period 1901 to 2015 were studied. During the period 2000-15, 2000, 2002, 2007, 2009, 2011, 2014 and 2015 were identified as drought year. EDI based drought monitoring was carried out and it was compared to that of SPI. The advantage, which EDI offers over SPI, was analyzed form the point of view of agricultural drought. The ability of EDI to identify the sub monthly drought was analyzed in comparison to that of SPI. Agricultural drought monitoring was carried out using different remote sensing indices like VCI, TCI, VHI, and SASI. The area under drought as per each index was compared to that of the EDI based drought area. Around $23 \%$ and $28 \%$ of total state area was found to be drought affected for the February fortnight of 2002. It was found that area under drought as monitored by SASI was found equivalent to that of EDI. Thus drought monitoring using SASI provides a reliable result as it takes into account the soil moisture factor also along with the vegetation factor.

using Shortwave Angle and Slope Index ( SASI ) data', pp. 9889-9902.

Department Of Agriculture, Cooperation \& Farmers Welfare. (2016). Annual Report. Welfare government of India Krishi Bhawan, New Delhi-110 001

Department of Agriculture and Cooperation. (2009, November).Manual for Drought Management.

WMO and GWP (2016) Handbook of drought indicators and indices. 
FAO Land and Water (2014).Drought. Retrieved from www.fao.org/nr/aboutnr/nrl

Food and Agriculture Organization of the United Nations (2015) 'The impact of disasters on agriculture and food security', p. 76.

Food Security Network Information. (March 2017).Global Report on Food Crisis.

Guttman, N. B. (1999) 'Accepting the Standardized Precipitation Index: a Calculation Algorithm1', JAWRA Journal of the American Water Resources Association, 35(2), pp. 311-322.

Hisdal, H., \& Tallaksen, L.M. (2003). Estimation of regional meteorological and hydrological drought characteristics: a case study for Denmark. Journal of Hydrology, 281, 230-247.

Khanna, S., Palacios-orueta, A., Whiting, M. L., Ustin, S. L., Riaño, D. and Litago, J. (2007) 'Development of angle indexes for soil moisture estimation, dry matter detection and land-cover discrimination', 109, pp. 154-165.

Kogan, F.N. (1995). Droughts of the late 1980s in the United States as derived from NOAA polar orbiting Satellite data. Bulletin of the American Meteorological, 76 (5), 655-668.

Mishra, A.K., \& Singh, V.P. (2010). A review of drought concepts. Journal of Hydrology, 391, 202-216.
Palacios-Orueta (2005). Assessment of NDVI and NDWI spectral indices using MODIS time series analysis and development of a new spectral index based on MODIS shortwave infrared bands. Remote sensing and Geoinformation processing in the assessment and monitoring of land degradation and desertification, 207224.

Quiring, S. M. and Ganesh, S. (2010) 'Evaluating the utility of the Vegetation Condition Index (VCI) for monitoring meteorological drought in Texas', Agricultural and Forest Meteorology, 150(3), pp. 330-339.

Shah, R., Bharadiya, N. and Manekar, V. (2015) 'Drought Index Computation Using Standardized Precipitation Index (SPI) Method For Surat District, Gujarat', Aquatic Procedia. Elsevier B.V., 4(September), pp. 1243-1249.

Tsiros, E., Domenikiotis, C., Spiliotopoulos, M. and Dalezios, N. R. (2004) 'Use of Noaa / Avhrr-Based Vegetation Condition Index ( VCI ) and Temperature Condition Index ( TCI ) for Drought Monitoring in Thessaly, Greece', EWRA Symposium on water resources management: risks and challenges for the 21st century, (July), pp. 1-10.

United Nation Children's Fund. (2015). Drought in India. New Delhi.

Zhang, X., Obringer, R., Wei, C., Chen, N., \& Niyogi, D. (2017). Droughts in India from 1981 to 2013 and Implications to Wheat Production. Scientific Reports. 